This item was submitted to Loughborough's Research Repository by the author.

Items in Figshare are protected by copyright, with all rights reserved, unless otherwise indicated.

\title{
Professional relations in sport healthcare: workplace responses to organisational change
}

PLEASE CITE THE PUBLISHED VERSION

http://dx.doi.org/10.1016/j.socscimed.2010.11.016

PUBLISHER

(C) Elsevier Ltd.

VERSION

AM (Accepted Manuscript)

LICENCE

CC BY-NC-ND 4.0

REPOSITORY RECORD

Malcolm, Dominic, and Andrea Scott. 2019. "Professional Relations in Sport Healthcare: Workplace Responses to Organisational Change”. figshare. https://hdl.handle.net/2134/15316. 
This item was submitted to Loughborough's Institutional Repository (https://dspace.lboro.ac.uk/) by the author and is made available under the following Creative Commons Licence conditions.

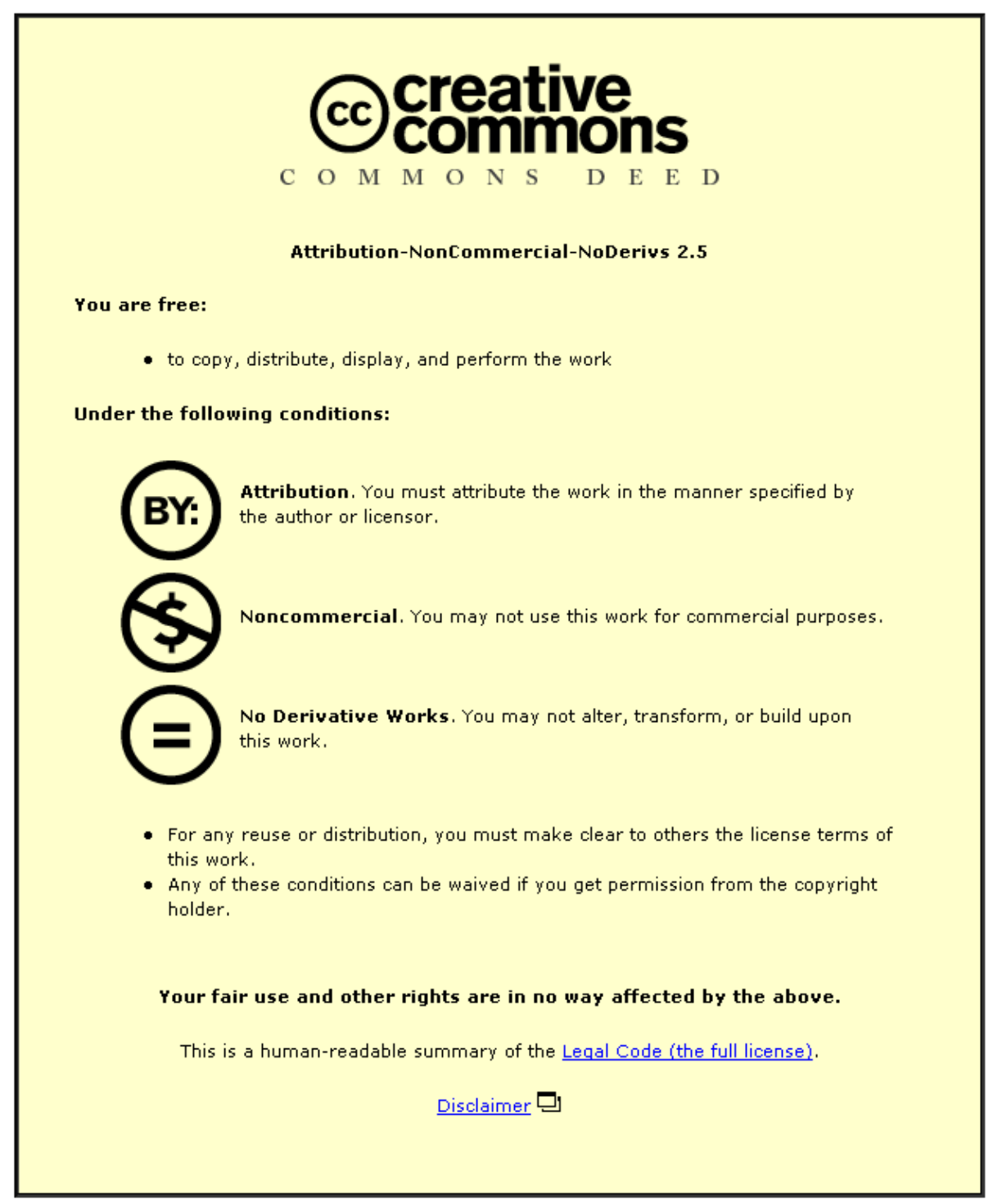

For the full text of this licence, please go to: http://creativecommons.org/licenses/by-nc-nd/2.5/ 


\title{
Professional Relations in Elite Sport Healthcare: Workplace Responses to Organisational Change
}

\begin{abstract}
This article examines the impact of organisational changes in UK elite sport on the professional relations among and between different healthcare providers. The article describes the processes by which demand for elite sport healthcare has increased in the UK. It further charts the subsequent response within medicine and physiotherapy and, in particular, the institutionalisation of sport specific sub-disciplines through the introduction of specialist qualifications. Drawing on semi-structured interviews, the article argues that organisational changes have led to intra-professional tensions within both professional groups but in qualitatively different forms reflecting the organisational traditions and professional identities of the respective disciplines. Organisational changes promoting multi-disciplinary healthcare teams have also fostered an environment conducive to high levels of inter-professional cooperation though significant elements of inter-professional conflict remain. This study illustrates how intra-professional relations are affected by specialisation, how legitimation discourses are used by different professions, and how intra- and inter-professional conflict and cooperation should be seen as highly interdependent processes.
\end{abstract}

Keywords: sports medicine; sports physiotherapy; intra-professional relations; interprofessional relations; legitimation discourses 


\section{Introduction}

The association of sport with health has led to a commonsense assumption that participants required minimal medical assistance. This idea is now routinely debunked by sociologists of sport. Waddington (2000), for instance, notes that while there is compelling evidence linking exercise with health benefits, the links between sport and health, and elite sport and health in particular, are problematic. According to Young (1993), "by any measure, professional sport is a violent and hazardous workplace, replete with its own unique form of 'industrial disease’” (p. 373). As elite athletes have come to be viewed as a discrete population with distinct medical needs, so sport-specific healthcare professions have emerged. This article analyses the impact of these developments upon intra- and inter-professional relations.

Initial analyses of the social organisation of sports medicine emphasised the 'peculiarity' of sport as a medical workplace (Walk, 1997). Peculiarity in these contexts is manifest in the relative absence of clinical autonomy (Waddington, 2000), the tripartite negotiation of treatment between clinicians, athletes and managers (Safai, 2003), and the pressures clinicians experience in relation to patient confidentiality (Waddington \& Roderick, 2002). Kotarba (2001) has drawn parallels between sports medicine and occupational medicine. For Theberge (2008), the defining features of sports medicine are its performance and consumer orientations.

Relations between different health professionals is a further aspect of this perceived peculiarity. Malcolm (2006a) argued that the status of club doctors in English rugby union was in part determined through the negotiation of occupational boundaries with 
physiotherapists. Safai (2007) links the demise of the Sports Medicine and Science Council of Canada to a failure to resolve tensions over professional inclusion/exclusion. Theberge (2008; 2009a) has discussed the blurred occupational boundaries between, and the jurisdictional narratives used by, athletic therapists, physiotherapists and chiropractors working with Canadian elite athletes.

In addressing relations between doctors and physiotherapists who provide medical support for UK Olympic athletes, this article contributes to the emerging sociological analysis of elite sport healthcare. Centrally, however, this study focuses on the impact of policy and organisational development upon professional relations and, in so doing, more broadly contributes to our understanding of the dynamics of intra- and interprofessional relations.

\section{Professional Boundaries}

Contemporary studies of healthcare professions have eschewed the "simplistic models of medical dominance” (Allen, 1997, p. 498) which characterised earlier research. A catalyst to this movement is Abbott's The System of Professions (1988). Professions are based on the control and application of knowledge, but their existence, Abbott argued, necessarily entails inter-professional relations with rival and competing groups. Professions “make up an interacting system” (Abbott, 1988, p. 33) of jurisdictional claims and vigorously defend potential incursions into their respective jurisdictions. Jurisdictional claims constitute "the determining history" of professions (Abbott, 1988, p. 2). "Professions develop when jurisdictions become vacant" 
(Abbott, 1988, p. 3) and professions evolve as a result of their inter-relations with other professions.

Consequently there has been a marked increase in the number of comparative studies of professional groups in recent years. Reviewing this literature, Bourgeault, Benoit and Hirschkorn (2009) reveal that six of the ten most examined professions are healthcare providers. The prominence of medicine (the most scrutinized occupation) is perhaps less surprising than the relative neglect of physiotherapy which is the thirteenth most frequently cited healthcare profession and twenty-ninth overall. This statistic reflects a wider social science neglect of the "first and largest profession allied to medicine” (Nicholls \& Cheek, 2006, p. 2337).

The growth of comparative studies of professional groups is also indicative of the changing context of professional practice. Though not unique to healthcare, the often cited driving forces behind these developments (new technologies, governmental drives towards cost efficiency, changing notions of the role of citizen-consumers), are particularly prominent in contemporary medicine. Studies have therefore examined the role of technology as a symbolic marker between competing health professions (e.g. Timmons \& Tanner, 2004), illustrated how health professionals' “identity-work" has developed in increasingly managed working environments (e.g. Charles-Jones, Latimer \& May, 2003, p. 74), and highlighted the ways in which changing consumer patterns influence medical dominance and inter-professional competition (Hartley, 2002). 
Nancarrow and Borthwick's (2005) typology of the dynamics of professional boundaries in healthcare recognises that professional boundaries may be subject to both intra- and inter-disciplinary change. Intra-disciplinary change may come about through diversification, stimulated by the establishment of new markets, new forms or philosophies of service delivery, or the adoption of new technologies or techniques. Specialisation, normally instituted through post-registration level qualifications and restrictive membership groups, can also lead to intra-disciplinary change. The establishment of both sports medicine and sports physiotherapy as sub-fields in their respective disciplines are examples of intra-disciplinary boundary change through specialisation.

Inter-disciplinary change involves either vertical or horizontal substitution. Vertical substitution entails a challenge to the status hierarchy with a provider group, often as an extension of working with an existing user group (i.e. specialisation), adopting tasks normally undertaken by those of another profession. Malcolm's (2006a) examination of the respective roles of doctors and physiotherapists in rugby union, where "physiotherapists do not simply assist doctors, but in many cases display considerable autonomy” (p. 388), is an example of vertical boundary blurring between health professions in sport. Horizontal substitution comprises the encroachment into the duties normally undertaken by a profession of a similar status, as illustrated in Theberge's (2008; 2009a) analysis of Canadian multi-disciplinary sports healthcare teams. Inter-disciplinary change is likely to become increasingly common as interprofessional practice and training expand and will occur, as indicated by Abbott, where jurisdictions are poorly defined and/or unprotected by regulation. Such change may be a pragmatic response to situational factors such as staffing and funding 
shortages. In sport, professional boundaries may be challenged in the pursuit of performance goals (Theberge, 2009a).

Nancarrow and Borthwick (2005) further note that the everyday lived experiences of professional boundaries are often less conflict-ridden than assumed. Allen (1997), in her study of nursing-medical staff relations, attributed inter-professional cooperation to the "organisational turbulence" of hospital work with the relative transience/permanence of doctors and nurses respectively, the temporal-spatial organisation of nursing and medical work (e.g. nurses' more continuous contact with patients), and the largely patient driven flow of work. Carmel's (2006) study of professional relations in an Intensive Care Unit (ICU) further illustrated how crossprofessional identity can be fostered in working environments which are physically separated from other aspects of medicine, and in which interaction is frequent. Within the ICU, "an occupational division of labour is rhetorically and practically obscured, while an organisational division is rhetorically and practically reinforced” (Carmel, 2006, p. 155).

Despite the “convergence and incorporation” (Carmel, 2006, p. 155) identified in such contexts, elements of conflict remain. Norris's (2001) analysis of the jurisdictional narratives of competing musculo-skeletal treatment providers emphasised three main themes: limitation (of others), holism (of one’s own techniques), and prevention (through the treatment of causes rather than symptoms). Sanders and Harrison (2008) identified various professional "legitimation discourses", including: reference to the scientific basis of work; identification of particular skills and expertise; the holistic and patient-centred nature of practice; the provision of care and emotional support; 
organisational efficiency and accountability; and claims to competence. The differences between the discourses specific professions use are, they noted, "striking” (Sanders \& Harrison, 2008, p. 304).

As Martin, Currie and Finn (2009) note, relatively few studies contextualise the discourses groups use to legitimate their jurisdictional claims within technological developments or policy change (exceptions include Lupton, 1997; Jones \& Green, 2006). The value of such studies, however, is that they combine relatively abstract macro-level claims about professions with substantive micro-level changes in everyday practice. While both Allen and Carmel discuss the broader policy context of nursing and ICU respectively, neither specifically seek to investigate the impact of policy on professional relations. The neglect of intra-professional relations is also identified as a characteristic of this field (Martin, Currie \& Finn, 2009). Sanders and Harrison's (2008) analysis of the legitimacy claims of cardiologists, geriatricians, GPs and specialist nurses in heart failure care is a notable exception, as is Martin, Currie and Finn's own work on the divisions between GPs with a specialist interest in genetics and geneticists.

This paper responds to these critiques by examining how the changing organisational context of healthcare provision in UK sport has affected the intra-professional relations within both sports medicine and sports physiotherapy, as well as the interprofessional relations between these respective groups. It seeks to understand the interrelationship between the macro and the micro, between policy formulation and workplace experience, between the structure of different professions and the local deployment of jursidictional discourses, and between conflictual and collaborative 
professional practice. Before addressing the dynamics of these professional relations we briefly discuss the broader policy context of sports medicine in the UK.

\section{The Development and Policy Context of Athlete Healthcare in the UK}

Sports medicine is defined by patient demographics rather than an organ system or specific disease. Historically this has left sports medicine open to a significant degree of intra- and inter-professional boundary contestation. For instance, in 1991 Physician and Sports Medicine reported that 82 different US groups considered themselves involved in the delivery of 'sports medicine'. Tellingly the American College of Sports Medicine describes its role as "bringing together experts in multiple disciplines”. In the UK, the development of sports medicine is perceived to have been hampered by continual resistance from the medical establishment (Reynolds \& Tansey, 2009). Consequently, definitions of sports medicine are unusually broad. Ryan (1989, p. 13) identifies, "physicians, coaches, trainers, exercise physiologists, psychologists, sociologists, physical educators and others whose special interests are less well-defined” as potential sports medicine providers. Both horizontal and vertical boundary blurring are therefore central characteristics of the development of athlete healthcare.

The British Association of Sport and Medicine (BASM) was founded in 1952. Sports medicine in the UK has been described as traditionally holding a "cinderella status ... practised away from mainstream medicine as a hobby or in the domains of private practice and physiotherapy" (Batt \& Macleod, 1997, p. 621). Empirical studies support this view. For instance Waddington, Roderick and Naik (2001) highlighted 
how many professional football club doctors were unpaid GPs with limited or no sports medicine training or prior experience. Malcolm (2006b) found a similar pattern amongst rugby union club doctors but contrasted this with the considerable specialist expertise of physiotherapists servicing the game. Olympic sports have also largely depended on the services of voluntary team doctors (Green \& Houlihan, 2005), and Carter (2009) argues that this reflects a tradition of civic obligation within the medical profession in Britain, indicative of the traditional coupling of vocationalism and professionalism in general practice (cf. Jones \& Green, 2006). Continuing debate about whether BASM should be a doctor-only or multidisciplinary body (Reynolds \& Tansey, 2009) is indicative of boundary blurring.

The legacy of amateurism has proved difficult to discard. While The British Journal of Sports Medicine was established in 1966, the National Sports Medicine Institute in 1992, and the sports medicine section of the Royal Society of Medicine in 1994, the development of sports medicine in the UK was restricted by the absence of a "single respected voice to coordinate education, research, service provision and accreditation” (Batt \& Macleod, 1997, p. 621). BASM has essentially acted as a "representative body as opposed to a regulatory one” (Carter, 2009, p. 71).

Sport national governing bodies (NGBs) and government agencies began to bemoan the underdeveloped state of sports medicine in Britain from the late 1980s. In 1988 the Sports Council argued that, "the need has never been greater for British sportspeople ... to have access to adequate medical and scientific support when and where they need it” (cited in Green \& Houlihan, 2005, p. 139. See also Carter, 2009). Further impetus came through the government's publication of plans to establish an 
“academy” to co-ordinate elite sport development (DNH, 1995). The subsequent UK Sports Institute (UKSI) would, according to Minister for Sport, Tony Banks, “professionalise” UK sport and establish a "medals factory” (Theodoraki, 1999). In 2002 the UKSI was restructured as the Home Countries Institutes of Sport (HCIS) and by 2005 Green and Houlihan would note that, “an integrated, multi-disciplinary sports science and sports medicine programme is now emerging” (2005, p. 139). Funding for Summer Olympic sports has risen from $£ 70$ million in the four years up to 2004 (Athens), to £235 million prior to 2008 (Beijing), and is expected to reach £261 million in the run up to London 2012 (www.uksport.gov.uk/pages/investment-insports/). The resourcing of medical support for the UK's elite athletes has never been greater.

In Sport and Exercise Medicine: policy and provision (BMA, 1996) the British Medical Association responded to this developing policy context and outlined an agenda for change. In 1998 BASM was reformed into BASEM (the British Association of Sport and Exercise Medicine), an intercollegiate academic board was established (MacLeod, 1999) and in 2005 'Sport and exercise medicine' was recognised as a medical speciality within the NHS. While a key stimulus for change is the demand for elite sport provision, state mandate has only been secured through embracing the physical activity for public health agenda (Batt \& Cullen, 2005).

Sports physiotherapy has developed along a similar trajectory. The Association of Chartered Physiotherapists in Sports Medicine (ACPSM) was founded in 1972 as a clinical interest group within the Chartered Society of Physiotherapy (CSP). In 2000 the ACPSM founded a quarterly journal (Physical Therapy in Sport). Responding in 
part to regulation by the Health Professions Council, the ACPSM has developed a three-tier membership largely based on continuing professional development (CPD). The ACPSM's rationale for embracing these changes is to respond to the increased demand for elite sport healthcare, and move away from a reliance upon sports physiotherapists who worked in an "honorary position as a hobby" and thus had "little proof of specialised professional competence" (www.acpsm.org/cpd.asp). In addition to ACPSM accreditation is the British Olympic Association (BOA) Elite Sport Register, designed to "demonstrate that members are committed to professional excellence” (BOA, 2006). Registration requires relevant work experience, references from both clinicians and elite sport representatives, and postgraduate qualification. Sports physiotherapy is seen as an area well placed to respond to the nation's future healthcare needs due to the increasing governmental emphasis on promoting health through physical activity (CSP, 2008).

\section{Research Methods}

The research sample consisted of members of the BOA Medical Committee and BOA Physiotherapy Forum. Each of the 35 Olympic sport NGBs nominates one representative to each committee. As the organisation of medical support was anticipated to vary depending on a sport's funding, media prominence, etc., this sample was chosen to provide data on clinicians across a range of bureaucratically complex and wealthy sports.

After gaining ethical approval at the researchers' employing institution, a two phase research method was employed. First, questionnaires were used to ascertain the 
methods of appointment, qualifications, experience and CPD of the respective groups. Further questions investigated motivations and work routines. A draft questionnaire was piloted with doctors and physiotherapists employed at the Olympic Medical Institute. The final questionnaire consisted of 23 closed and 4 open-ended questions. Descriptive statistical analysis of the former was conducted using SPSS. A central aim of the questionnaire was to provide data which could be compared to prior studies of clinicians working in UK sport (Waddington, Roderick \& Naik, 2001; Malcolm, 2006b). In this respect, the sample of sport clinicians which forms the focus of this paper could be said to be the most highly skilled and sport-specific group yet to be researched in the UK. A secondary aim of the questionnaire was to enable participants to volunteer for the more qualitative, interview phase of the study.

Doctor questionnaires were distributed by post by the Chair of the Medical Committee. A total of 21 doctors returned questionnaires (posted directly to the researchers). This constituted a response rate of $60 \%$, but as questionnaire analysis revealed that some doctors represented multiple sports, 75\% of Olympic sports were represented. Attempts were made to interview all of the eighteen doctors who initially volunteered to participate further in the study, though ultimately fourteen interviews (11 male, 3 female) were conducted. Of these, six identified themselves as primarily working in non-sport-specific medicine (three GPs and three hospital consultants), four as full-time sports medicine specialists (three employed by the HCIS, one by the BOA) and four whose work was split between sport (mainly HCIS) and non-sport practice. 
Questionnaires were also distributed to 34 email contacts provided by the Chair of the Physiotherapy Forum. Of the twenty physiotherapists who responded to an initial email and subsequently returned questionnaires, sixteen volunteered to be interviewed. It proved possible to arrange interviews with fourteen of these respondents (5 male, 9 female). Seven interviewees worked full-time with the HCIS, one was semi-retired but worked part-time with the HCIS, and six cited private practice as their main source of income.

'Semi-structured' interviews were conducted by the second author. They explored themes such as: relationships with other clinicians, coaches and athletes; contrasts in the management of athletes' pain and injury during routine training and major competitions; and reflections on the development of sports medicine, sports physiotherapy and medical provision for elite athletes. Transcription took place as soon as possible after interview, and enabled the researchers to reflect upon emergent findings. By developing the interview schedule in this way, the researchers were able to refine the questions so that they would better relate to respondents' subjective experiences (Burgess, 1984). Data were analysed using thematic coding, with emergent themes and sub-themes identified according to their frequency and the degree to which they resonated with ideas expressed in the established literature (Flick, 2009). Data were subsequently abstracted from the interview transcripts and placed in separate files to provide cross-participant comparison. Respondents’ gender and sport affiliations are not reported to preserve anonymity (for further details see Scott, 2010). 
The findings are presented under two main headings. The first looks at the impact of moves towards specialisation in sports medicine and sports physiotherapy and charts the degree to which this has led to internal fragmentation within the respective professions. The second examines the balance between conflicting and cooperative inter-professional relations as a consequence of organisational change.

\section{Findings: Intra-professional relations in elite sport healthcare}

\section{Sports Medicine Doctors}

Interviewees argued that an emphasis on sport-specific qualifications had improved standards of medical practice and occupational opportunities. Specialist qualifications had become the primary appointment criteria and increasingly job descriptions were written by medical staff rather than sports administrators or coaches. This led to the creation of a new type of 'professional'. One doctor said that those with specialist qualifications had "created their [own] network and their own set of standards". Others expressed pride in the sense of legitimacy they felt, noting that, "it's nice to feel like you are right on top of all of it [sports medicine]”.

Professional identity has developed in contradistinction to beliefs about the limitations of those amateur volunteers who historically provided medical support to athletes. All interviewees made a clear distinction between those who were employed by the HCIS (and were therefore assumed to have sport-specific qualifications) and those who were 'merely' appointed by NGBs. As one doctor noted, the establishment of the HCIS had enabled some practitioners to gain considerable experience of a wide variety of sports injuries and thus created "specialist specialists". The interviewee went on to refer to 
NGB doctors as "under-qualified", with "limited training”. Such was their limited exposure to, and experience of, patients from elite sport that this interviewee argued that “an NGB doctor ... isn't a specialist”. Others extended this narrative by questioning the legitimacy of those without relevant qualifications and defining their presence as potentially harmful to the professional specialism. One doctor stated, "What I think is no longer acceptable is to have people who have a self-declared interest in sport and exercise medicine who have no added qualification ... I think it is confusing for patients and athletes”. Specialisation, educational qualification and expertise were depicted as a triad.

This ideological fragmentation of sports medicine has led to the movement of nonspecialist qualified doctors into increasingly peripheral roles or out of sports medicine entirely. Doctors acted on the intra-professional distinctions they drew, one categorically stating that “my athletes don't see anybody who doesn't have one [sports medicine qualification], full stop". Others noted that, consequently "the relationships with the NGB [doctors] can be difficult”. Pointing to broader concerns about a lack of legitimacy, one HCIS doctor similarly described how NGB doctors have "got to try and justify their existence at times”. Intra-professional tensions were therefore mediated by a belief that one group of practitioners provided "a gold standard” which others failed to live up to (Martin, Currie \& Finn, 2009, p. 1195. See also Theberge, 2009a).

Some interviewees spoke of their experience of marginalisation. An NGB doctor described how their role with athletes had altered as a result of structural changes to sports medicine: 
It didn’t matter so much before but ... it's probably getting to the point now where any doctor who is going to examine and investigate and recommend treatment for an athlete, particularly a top-class athlete, needs to have a proper sports medicine qualification and be on the professional register. So doctors now have to tread a bit more carefully ... be careful not to step out of your own comfort zone.

There was, however, no explicit questioning of the legitimacy of equating formal qualifications with expertise. Indeed another NGB doctor described the existence of formal qualifications and a recognised professional pathway as "very good news".

Individuals have strived for specialist status as they have sought to service a new market (cf. Nancarrow \& Borthwick, 2005). The recognition of specialist status, with employers attaching greater value to formally accredited, as opposed to experiential, knowledge has thus created a hierarchy within the sub-discipline. The emergent elite has attempted to distance itself from the broader membership. While some intraprofessional tension is evident, marginalised members appear relatively resigned to their fate and view the status of their newly qualified counterparts as legitimate.

\section{Sports Physiotherapists}

Physiotherapists also noted how the changing policy context had led to a more structured career pathway, with better financial rewards and greater job security. They argued that postgraduate qualifications, and an MSc in sport physiotherapy in particular, were "becoming more and more important for you to progress”, as “certain key roles in sport pretty much demand it [an MSc] now”. Another suggested that: 
Physiotherapy, as a whole, is very much being pushed in that direction. Anybody can say "I can do this, I can do that", but if you have got it written on a piece of paper then you can show that you have it as a qualification.

Many physiotherapists however expressed reservations at the 'academicisation' of their specialism. For example one senior physiotherapist noted, "I would never have chosen to do it [the MSc]. I think there was a bit of pressure put on me”. Another described similar motivations and explicitly questioned the value of the qualification:

The only reason I am doing it is because I have to do it. I'm not doing it because I want to do it. I love my profession and I want to keep doing what I am doing but I can't do that unless I do these stepping stones. It annoys me that I have already got the experience ... I don't see why a piece of paper is going to make me a better physiotherapist.

Again the dominant intra-professional discourse was in relation to expertise, but the question of which knowledge counted was pronounced amongst physiotherapists. For instance, invoking the jurisdictional rhetoric of limitation (Norris, 2001), a number of interviewees described younger sport-specialists as inferior due to their restricted scope of practice: "Physiotherapists are specialising far too early in sports. A lot of very nice, young physiotherapists who have got more qualifications ...but they have not got that background experience”.

Physiotherapists expressed concerns about the pursuit of sport-specific qualifications at the expense of experientially acquiring core physiotherapy skills. One suggested that "a good sports physiotherapist has to be a good physiotherapist first and foremost 
and then specialise in the sports area”. Reflecting upon specialisation another stated, "Yes you need the qualifications and yes you definitely need the ongoing education, but you also need those very basic background skills of communication and those kinds of things”. Indeed, a number of interviewees argued that those physiotherapists whose professional status was based on academic specialisation had missed out on important 'character building' experiences of standing “on a muddy pitch ... for the love of it" which university-educated physiotherapists "aren't prepared to do ... without payment”.

Thus commitment and experience rather than qualifications were equated with expertise. In contrast to the rationale for change proposed by the ACPSM, the developing 'professional' culture, in which service was expected to be financially rewarded, was perceived to restrict "the ability to get the right people in [sports physiotherapy]”. Some noted the initial scepticism towards, and reluctance to join, the HCIS from within physiotherapy. Consequently, while the HCIS "used to try and convince everybody that they had the best people working for them ... in actual fact I'm not sure that they are”. A physiotherapist who described the situation as "all a bit upside-down" argued that while some "might have had more managerial experience [that] doesn't make them clinicians”.

Sports physiotherapy, like sports medicine, is internally divided by policy driven occupational change. HCIS managerial roles are awarded to physiotherapists with specialist qualifications, leading those with greater practical experience to resent the higher pay, and question the expertise, of their 'superiors'. Specialisation has served to divide the emergent professional group. These intra-professional relations are both 
relatively pronounced and mediated by a discourse in which the basis of 'expertise' is explicitly contested.

\section{Findings: Inter-professional relations in elite sport healthcare}

Inter-professional jurisdictional claims are at a nascent stage in the emergent system of elite sport healthcare in the UK. As noted above, the definitional ambiguity and stilted organisational development of sports medicine leaves members of these professional groups without the institutional buttresses which more typically shape professional boundary work (Abbott, 1988). Doctors and physiotherapists working in sport will be influenced by the jurisdictional precedents established between their parent disciplines, but also a shared interest in, and experience of, promoting sport healthcare as both a distinct and legitimate field.

The establishment of multidisciplinary HCIS teams has done much to foster interprofessional cooperation. One doctor noted that:

As an umbrella it suddenly brought together practitioners that were then able to set up clinical governance documents for sports medicine, able to pull together training in terms of CPD sessions and [provide] a protected environment, a network set-up I guess for systems of inquiry and surveillance and things like that.

Central to this multi-disciplinarity was an emphasis on "close, routine and collaborative work" (Carmel, 2006, p. 162). According to one physiotherapist, “we are very much about a team effort ... We will be making decisions in conjunction with the doctor, the strength and conditioning coach, the coach at least, if not others”. 
Interviewees frequently described inter-professional relationships as mutually supportive, referring to the widespread trust and lack of conflict between different practitioners. Some attributed this to regular physical interaction, "because you see them all of the time, it is kind of a team environment” (doctor), others to a common identity forged from "shar[ing] very similar philosophies" (doctor). One doctor implicitly noted how these arrangements might contrast with traditional perceptions of medical dominance:

I think doctors have to be a little bit careful of being holier than thou and think they can operate from their ivory tower. If you do that you will just disenfranchise everybody and end up not helping the athlete and that's not good.

Respondents stressed the importance of inter-professional equity. One doctor stated that relations were "non-hierarchical and everybody has got their own skills and you just have to take a bit of everything really". Another described how "everyone has some input ... you should be inclusive rather than exclusive”. Indeed, the way that clinicians dressed served to obscure occupational boundaries, while also effectively bolstering an organisational boundary. As one physiotherapist noted: “you're both with the same team, you're wearing the same tracksuit, you have got the same purpose”. In this respect, sports medicine doctors exhibited similar behaviour to ICU consultants who obscured their rank by wearing "theatre greens" on the ward (Carmel, 2006, p. 161). 
Cooperation was more evident than conflict when interviewees identified the respective professions’ jurisdictional domains. Physiotherapists described prescription and making “final” diagnoses as doctors' primary areas of responsibility, and ongoing health care such as injury prevention and injury rehabilitation as the domain of physiotherapists. According to one physiotherapist, "They [doctors] lead on the medical side. So if it was a case of injecting, giving drugs, that sort of thing then yes, they rule. But if it was a rehabilitation thing then I think we lead”.

The temporal-spatial organisation of athlete healthcare was identified by both doctors and physiotherapists as fundamental to the physiotherapist's contribution to multidisciplinary sport healthcare (see also Malcolm, 2006a). In this respect, the division of labour was seen as a pragmatic response to situational factors, and time constraints in particular. Invoking narratives of holism and limitation (Norris, 2001), one physiotherapist noted, “you're constantly with them [athletes]. The doctor might come in for a time and go away again but you spend time with them". Physiotherapists talked of being "involved in every step", the significance of the psychological work they undertook, and the importance of athletes knowing that, "you are always going to be there for them”.

Yet while the division of labour described by sports physiotherapists complied with the professional boundaries which have historically existed between physiotherapy and medicine (Larkin, 1983), what was perhaps unusual was the degree to which doctors spoke of their own limitations relative to sports physiotherapists. One doctor outlined how they saw the respective roles and thus occupational boundaries: "I'm the lead medical person but the thing is the physiotherapist is full-time and I'm not so 
they are the ones that will be there seeing the players every day”. Another, expressed a degree of reluctance in accepting what Allen (1997, p. 511) describes as de facto boundary blurring:

The physiotherapists will know an awful lot more about what is going on with athletes because they have the opportunity to be out there seeing what is going on and they get talked to a lot more so you have to kind of have them in and give them respect and work with them closely. (Emphasis added).

Thus this was not simply a case of "the day-to-day exigencies of getting work done mean[ing] that formal professional boundaries cannot be strictly maintained” (Sanders \& Harrison, p. 290), for doctors were prepared to explicitly defer to physiotherapists’ expertise. When asked about their experiences of inter-professional working, another responded: “I work with an excellent physiotherapist, often I'll spend time watching him anyway because he is just so good. So he is an education, so I nick as much as I can from him”. Implicitly recognising the degree to which their respective skills impinged upon the professions' respective jurisdictions, one doctor stated "in a way you kind of get a bit de-skilled”.

Inter-disciplinary boundary blurring was particularly apparent when medical support for athletes in regular training was contrasted with the support given to athletes in competition. Due to cost considerations, and the belief that the majority of injury problems were likely to be musculoskeletal, physiotherapists were more likely than doctors to travel with athletes to competitive events (see also Theberge 2009b). Here they were asked to undertake both non-medical tasks (e.g. driving vehicles, ordering breakfast) and an expanded range of medical duties. As one physiotherapist put it, “we have never had enough money to send a doctor so ... I have to do everything. I'm 
the doctor, I'm the physiotherapist, I'm the whatever”. Consulting with the team doctor by telephone was an important token of the traditional medical hierarchy but, as one doctor noted, "I'll advise them on the phone quite a lot ... [but] the physiotherapist does a lot of the medical things". While on the one hand physiotherapists generally felt that, "I would make the call if I'm on my own ..." the rider that, “... but if there is a doctor there and it is a serious injury, it is always nice to have a discussion”, suggests that physiotherapists are conscious of the contextspecific nature of the legitimacy of their jurisdictional boundary.

This opened up the possibility of a more significant challenge to the traditional medicine-physiotherapy status hierarchy. Interviewees argued that their more continuous working relationship with athletes placed them on an equal footing with doctors, or even made them primary healthcare providers. In this respect, physiotherapists conceived inter-professional relationships rather differently to the way doctors expressed them. According to one: "The doctor will come in and help with the diagnosis but as far as treatment goes, spending time with the athlete is central and so the physiotherapist tends to spend a lot more time with the athlete" (Emphasis added). Empowered by the organisational context in which they practised, physiotherapists questioned the authoritative nature of doctors' knowledge. A second physiotherapist argued that doctors,

just don't have the time, nor the knowledge, to a large degree ... specific knowledge of what is going on at various joints ... Mostly, they have no idea what is going on so they will chuck someone off to a physiotherapist and they will say "it's this, that and the other”, and it is nothing like that at all. 
Despite such challenges an inter-professional hierarchy was largely accepted by physiotherapists who argued that the source of medical dominance lay not in doctors' expertise, but through their positioning in a broader (sports) medicine network. One physiotherapist, though generally critical of a particular doctor's lack of sportspecialisation, justified their cooperative relations because the doctor was seen to be able to "access more things". Others spoke specifically about doctors' roles, and by implication importance, being demarcated through the provision of drugs (i.e. prescription and injection) and technology (particularly, MRI scans). Hence doctors were "always the important ones to keep together ... they're the ones who will be referring to consultant opinions”. While areas of negotiation remained, particularly around rehabilitation, physiotherapists saw such technology as providing doctors with a level of certainty which was largely beyond their attainment. MRI scans, for instance, could put diagnosis "beyond reasonable doubt" (physiotherapist). In contrast, the physiotherapist depicted rehabilitation as a relatively subjective process, with “question marks” over different rehabilitation routes. Physiotherapists’ limited access to broader networks of medical technology and support led one to argue that their work would inevitably "be in the background".

As others have noted, technology may feature in professions' jurisdictional claims. Timmons and Tanner (2004), for instance, illustrated the role of technology as discourse in the boundary disputes between nurses and Operating Department Practitioners; a group which, like those studied here, were in early stages of establishing their professional boundaries. Likewise, Norris (2001) argued that the use of machinery (ultrasound) was perceived to be part of physiotherapists' 'signature treatment' (relative to chiropractors, osteopaths and massage therapists). While the 
sports physiotherapists in this study reported a retreat from technology ("I used to take an ultrasound with me, but now I don’t bother ... in a competition setting it's not actually worth doing”), within elite sport healthcare the concession of technologicallybased dominance to doctors occurs in relation to access rather than deployment.

In physiotherapists' claims to such things as competence, organisational efficiency and patient-centred care, these findings replicate the "fairly clear inverse relationship" Sanders and Harrison identified between “occupations' respective location in the professional status hierarchy and the number and variety of legitimating discourses employed” (2008, p. 304). The negotiation of occupational roles is both enabled by the absence of de facto professional boundaries in the specific practice context, and constrained by de jure jurisdictional claims of the dominant (medical) profession. Everyday practice is shaped by the negotiation of new professional relationships as well as a renegotiation of inherited professional jurisdictions.

\section{Discussion}

The policy-led organisational changes outlined above have had a significant impact upon the relations both within sports medicine and sports physiotherapy, and between the respective specialisms. In assessing the influence of macrostructural issues on the micro-sociological aspects of the everyday experiences of healthcare providers (Lupton, 1997) a number of further points should be made. In particular, what does this study tell us about intra-professional relations, inter-professional relations, and the interdependence of the two? 
The comparison of intra-professional conflict which this case study affords is particularly revealing. Policy changes have internally divided the respective professions but along different fault lines. The professional identity of the selfperceived elite of sports medicine is reminiscent of a "new professionalism” identified as emerging within general practice. This identity consists of three core traits: "positioning yourself as one of a network of professional colleagues; an obligation to be clinically competent and constantly update knowledge, and a commitment to patient-centred and collaborative practice” (Jones \& Green, 2006, p. 941). Sports medicine doctors identified each of these as characteristic of their developing field and distinguished between themselves and (inferior) colleagues on the basis of the second trait. However, to some extent the descriptions of the work of these 'new' sports medicine specialists suggests a shift towards biomedical specialism rather than biographical or patient-centred forms of medical care (cf. Charles-Jones, Latimer \& May, 2003). This is not merely a case of “re-professionalisation” (Lupton, 1997) but of establishing a professional identity at a particular point in time, within a broader policy context.

The professional identities of sports physiotherapists are quite different, and thus so are their experiences of intra-professional conflict. Collaborative practice and patientcentredness were both identified as fundamental characteristics of sports physiotherapy, but physiotherapists more explicitly challenged the perceived benefits of prioritising formal qualifications over experiential knowledge. One could argue therefore that the notion of 'professionalism' adopted within sports physiotherapy is in contrast to contemporary trends, but additional factors also help explain this difference. First, legitimisation through education may be seen by sports 
physiotherapists as a regressive step, reminiscent of medicine’s history of dominance over physiotherapy and, in particular, the formers' validation of the latter through academic qualifications (Larkin, 1983; Nicholls \& Cheek, 2006). While educational qualifications have traditionally played a significant role in legitimising the status of medicine (thus making their adoption by a newly emerging sub-discipline likely), “physiotherapy has grown mainly out of practical experience” (Thornquist, 1994, p. 701). Second, academicisation contrasts with existing studies of physiotherapists' professional identities which appear to be based on offering various forms of treatment (Norris, 2001, p. 30) in the pursuit of problem resolution. Accordingly, physiotherapists "confirm their professional identities by doing something for the patient” (Thornquist, 1994, p. 709).

Although specialisation has led to contrasting intra-professional relations, uniting the strategies of sports medicine doctors and sports physiotherapists is a, "retrench(ment) behind the boundaries of their discursive fields and retreat towards the protected core" (Larson, 1990, cited in Sanders \& Harrison, 2008, p. 305). That is to say, it should be assumed that intra-professional relations will be shaped by the broader ideological traditions of the disciplines in which they occur.

The inter-professional relations discussed here replicate recent findings (e.g. Allen, 1997; Carmel, 2006), and refine Abbott's (1988) contention that professions will vigorously defend against potential incursions into their jurisdictional domains. However, this study suggests that the flexibility of inter-professional boundaries is not only influenced by contextual exigencies, but also a process of interactional learning. The status distinctions one would expect to see in relation to medicine and 
physiotherapy are evident in the identification of jurisdictional boundaries. Physiotherapists' notion of "final diagnosis" is interesting here, as is the desire to have their boundary incursions legitimated by doctors (e.g. through telephone consultation). But partly because it has the potential to enhance their own prestige (through the acquisition of new skills and knowledge), and partly because they feel they can preserve their dominant status on the basis of other work domains (drugs, technology and referral), doctors put up little explicit resistance to the relatively expanded work sphere of sports physiotherapists.

Additionally, given the significance of intra-professional relations, one would have to question Abbott's view that jurisdictional claims are the "determining history of the professions" (1988, p. 2. Emphasis added). Rather, the professional boundaries of sports doctors and sports physiotherapists are partly determined by the degree to which they rely, and have relied upon, cross-disciplinary cooperation in the process of legitimising their own area of specialism to their broader profession. With continued funding of elite sport healthcare in the UK contingent on the competitive success of the nation's athletes, the employment prospects of sports doctors and sports physiotherapists are necessarily intertwined.

\section{Conclusion}

The inter-professional conflict voiced by physiotherapists suggests that previous status gains and subsequent collaboration may have opened up an ideological headland' from which further contestation can develop. Concessions and professional boundary blurring at one point in time, or in one context, will constitute a subsequent 
set of social relations in which further jurisdictional contestation is enabled/constrained. Professional relations are therefore fundamentally processual. They should also be seen as a complex balance of conflict and cooperation within and between members of distinct groups.

This study has illustrated the importance of examining workplace relations in light of the broader working context, for the interdependence of intra- and inter-professional relations may make the consequences of policy change difficult to predict. Moreover, by comparing the jurisdictional domains and legitimacy discourses we gain additional explanatory purchase on the system of professions. In particular it becomes clear that inter-professional relations are not necessarily more conflictual than other sets of relations. The particular timing of the research relative to policy change, the radical nature of the policy change, and the distinct tradition of intra- and inter-professional boundary blurring in sports healthcare may make the processes identified with the emergence of these specialisms particularly marked. However, there is little reason to think that they are wholly different in kind to the micro-level professional relations invoked by policy-driven organisational change which occur in various contemporary professional settings.

\section{References}

Abbott, A. (1988). The system of professions: an essay in the division of expert labour. Chicago: University of Chicago Press.

Allen, D. (1997). The nursing-medical boundary: a negotiated order? Sociology of Health \& Illness, 19(4), 498-520. 
Batt, M. \& Cullen, M. (2005). Sport and exercise medicine in the United Kingdom comes of age. British Journal of Sports Medicine, 39, 250-251.

Batt, M. \& Macleod, D.A. (1997). The coming of age of sports medicine. British Medical Journal, 314, 621.

Bourgeault, I.L., Benoit C. \& Hirschkorn, K. (2009). Introduction: comparative perspectives on professional groups. Current Sociology, 57(4), 475-485.

British Medical Association (1996). Sport and exercise medicine: policy and provision. London: BMA.

British Olympic Association (2006). BOA register of chartered physiotherapists in elite sport: criteria and procedures. London: BOA.

Burgess, R. (1984). In the field: an introduction to field research. London: George Allen and Unwin.

Carmel, S. (2006). Boundaries obscured and boundaries reinforced: incorporation as a strategy of occupational enhancement for intensive care. Sociology of Health \& Illness, 28(2), 154-177.

Carter, N. (2009). Mixing business with leisure? The football club doctor, sports medicine and the voluntary tradition. Sport in History, 29(1), 69-91.

Charles-Jones, H., Latimer, J., \& May, C. (2003). Transforming general practice: the redistribution of medical work in primary care. Sociology of Health \& Illness, 25(1), 71-92.

Chartered Society of Physiotherapy (2008). Charting the future of physiotherapy. London: CSP.

Department of National Heritage (1995). Sport - raising the game. London: DNH. 
Flick, U (2009). An introduction to qualitative research. London: Sage (4 ${ }^{\text {th }}$ edition).

Green, M. \& Houlihan, B. (2005). Elite sport development: policy learning and political priorities. London: Routledge.

Hartley, H. (2002). The system of alignments challenging physician professional dominance: an elaborated theory of countervailing powers. Sociology of Health \& Illness, 24(2), 178-207.

Jones, L. \& Green, J. (2006). Shifting discourses of professionalism: a case study of general practitioners in the United Kingdom. Sociology of Health \& Illness, 28(7), 927-950.

Kotarba, J. (2001). Conceptualizing sports medicine as occupational health care: illustrations from professional rodeo and wrestling. Qualitative Health Research, 11(6), 766-779.

Larkin, G. (1983). Occupational monopoly and modern medicine. London: Tavistock.

Lupton, D. (1997). Doctors on the medical profession. Sociology of Health \& Illness, 19(4), 480-497.

MacLeod, D.A. (1999). The intercollegiate academic board of sport and exercise medicine. British Journal of Sports Medicine, 33, 73-74.

Malcolm, D. (2006a). Unprofessional practice? The status and power of sports physicians. Sociology of Sport Journal, 23(4), 376-395.

Malcolm, D. (2006b). Sports medicine: a very peculiar practice? Doctors and physiotherapists in elite English rugby union. In I. Waddington, B. Skirstad \& S. Loland (Eds.) Pain and injury in sport. Social and ethical analysis (pp. 165182). London: Routledge. 
Martin, G.P., Currie, G. \& Finn, R. (2009). Reconfiguring or reproducing intraprofessional boundaries? Specialist expertise, generalist knowledge and the 'modernization' of the medical workforce. Social Science \& Medicine, 68, 1191-1198.

Nancarrow, S. \& Borthwick, A.M. (2005). Dynamic professional boundaries in the healthcare workforce. Sociology of Health \& Illness, 27(7), 897-919.

Nicholls, D.A. \& Cheek, J. (2006). Physiotherapy and the shadow of prostitution: The Society of Trained Masseuses and the massage scandals of 1894. Social Science \& Medicine, 62, 2236-2348.

Norris, P. (2001). How 'we' are different from 'them': occupational boundary maintenance in the treatment of musculo-skeletal problems. Sociology of Health \& Illness, 23(1), 24-43.

Reynolds, L.A. \& Tansey, E.M. (Eds.) (2009). The development of sports medicine in twentieth century Britain. London: Wellcome Trust Centre.

Ryan, A.J. (1989). Sports medicine in the world today. In A.J. Ryan \& F.L. Allman (Eds.) Sports medicine. San Diego: Academic Press.

Safai, P. (2003). Healing the body in the 'culture of risk': examining the negotiation of treatment between sports medicine clinicians and injured athletes in Canadian intercollegiate sport. Sociology of Sport Journal, 20, 127-146.

Safai, P. (2007). A critical analysis of the development of sport medicine in Canada, 1955-1980. International Review for the Sociology of Sport, 42(3), 321-341.

Sanders, T. \& Harrison, S. (2008). Professional legitimacy claims in the multidisciplinary workplace: the case of heart failure care. Sociology of Health \& Illness, 30(2), 289-308. 
Scott, A. (2010). “More professional?” The occupational practices of sports medicine clinicians working with British Olympic athletes. Unpublished $\mathrm{PhD}$ thesis, Loughborough University, Loughborough, UK.

Theberge, N. (2008). The integration of chiropractors into healthcare teams: a case study from sports medicine. Sociology of Health \& Illness, 30(1), 19-34.

Theberge, N. (2009a). 'We have all the bases covered'. Constructions of professional boundaries in sport medicine. International Review for the Sociology of Sport, 44(2), 265-282.

Theberge, N. (2009b). Professional identities and the practice of sport medicine in Canada: a comparative analysis of two sporting contexts. In J. Harris \& A. Parker (Eds.) Sport and social identities (pp. 49-69). Basingstoke, UK: Palgrave.

Theodoraki, E. (1999). The making of the UK Sports Institute. Managing Leisure, 4, 187-200.

Thornquist, E. (1994). Profession and life: separate worlds. Social Science \& Medicine, 39(5), 701-713.

Timmons, S. \& Tanner, J. (2004). A disputed occupational boundary: operating theatre nurses and Operating Department Practitioners. Sociology of Health \& Illness, 26(5), 645-666.

Waddington, I. (2000). Sport, health and drugs: a critical sociological perspective. London: E\&F Spon.

Waddington, I. \& Roderick, M. (2002). The management of medical confidentiality in English professional football clubs: some ethical problems and issues. British Journal of Sports Medicine, 36, 118-223. 
Waddington, I., Roderick, M. \& Naik, R. (2001). Methods of appointment and qualifications of club doctors and physiotherapists in English professional football: some problems and issues. British Journal of Sports Medicine, 35, 4853.

Walk, S. (1997). Peer in pain: the experiences of student athletic trainers. Sociology of Sport Journal, 14(1), 22-56.

Young, K. (1993). Violence, risk and liability in male sports culture. Sociology of Sport Journal, 10(4), 373-396. 